\title{
Gold Nanoparticle-Decorated Single-Walled Carbon Nanotubes as a Catalytic Amplification Platform for the Electrochemical Detection of Alkaline Phosphatase Activity
}

\author{
Lingzhi Zhao ${ }^{1,2, *}$, Liu Zhao ${ }^{3}$, Yanqing Miao ${ }^{1}$, Chenxiao Zhang ${ }^{2, *}$ \\ ${ }^{1}$ College of pharmacy, Xi 'an Medical College, Xi 'an 710021, China \\ ${ }^{2}$ Key Laboratory of Analytical Chemistry for Life Science of Shaanxi Province, School of Chemistry \\ and Chemical Engineering, Shaanxi Normal University, Xi'an 710062, China \\ ${ }^{3}$ Beijing Research Center of Agricultural Standards and Testing, Beijing 100097, China \\ *E-mail: oldskyhappy_zlz@163.com
}

doi: $10.20964 / 2018.02 .04$

Received: 8 October 2017 / Accepted: 29 November 2017 / Published: 28 December 2017

The detection of alkaline phosphatase (ALP) activity is of great significance in many biomedical applications and for understanding the functional mechanism of ALP-related biological events. A sensitive electrochemical ALP biosensor using ascorbic acid 2-phosphate (AA-P) as the substrate was developed based on a gold nanoparticle-decorated single-walled carbon nanotube (GNP/SWNT)modified glassy carbon electrode (GCE). The activity of ALP was determined indirectly according to the concentration of ascorbate (AA), which was generated during the hydrolysis reaction of AA-P in the presence of ALP as a catalyst. The biosensor exhibited a low applied potential, high sensitivity and selectivity, and the current response increased with ALP concentration from 3 to $50 \mathrm{U} \mathrm{L}^{-1}$ with a detection limit of $0.2 \mathrm{U} \mathrm{L}^{-1}$. The applicability of the developed method was demonstrated for successfully detecting ALP in whole HeLa cell lysate, thus providing a promising tool for other sensing systems that involve ALP.

Keywords: Alkaline phosphatase activity, Gold particles, Single-walled carbon nanotubes (SWNTs), whole cell lysate.

\section{FULL TEXT}

(C) 2018 The Authors. Published by ESG (www.electrochemsci.org). This article is an open access article distributed under the terms and conditions of the Creative Commons Attribution license (http://creativecommons.org/licenses/by/4.0/). 